\title{
Antenatal depression and risk of gestational diabetes, adverse pregnancy outcomes and postpartum quality of life
}

Caro Minschart ${ }^{1}$, Kyara De Weerdt ${ }^{2}$, Astrid Elegeert ${ }^{2}$, Paul Van Crombrugge ${ }^{3}$, Carolien Moyson', Johan Verhaeghe ${ }^{4}$, Sofie Vandeginste ${ }^{5}$, Hilde Verlaenen ${ }^{5}$, Chris Vercammen $^{6}$, Toon Maes ${ }^{6}$, Els Dufraimont $^{7}$, Christophe De Block ${ }^{8}$, Yves Jacquemyn ${ }^{9}$, Farah Mekahli ${ }^{10}$, Katrien De Clippel ${ }^{11}$, Annick Van Den Bruel ${ }^{12}$, Anne Loccufier ${ }^{13}$, Annouschka Laenen $^{14}$, Roland Devlieger ${ }^{4}$, Chantal Mathieu', Katrien Benhalima ${ }^{1}$

'Department of Endocrinology, University Hospital Gasthuisberg, KU Leuven, Herestraat 49, 3000 Leuven, Belgium

${ }^{2}$ Medicine, KU Leuven, Herestraat 49, 3000 Leuven, Belgium

${ }^{3}$ Department of Endocrinology, OLV ziekenhuis Aalst-Asse-Ninove, Moorselbaan 164, 9300 Aalst, Belgium

${ }^{4}$ Department of Obstetrics \& Gynecology, UZ Gasthuisberg, KU Leuven, Herestraat 49, 3000 Leuven, Belgium

${ }^{5}$ Department of Obstetrics \& Gynecology, OLV ziekenhuis Aalst-Asse-Ninove, Moorselbaan 164, 9300 Aalst, Belgium

${ }^{6}$ Department of Endocrinology, Imelda ziekenhuis, Imeldalaan 9-2820 Bonheiden, Belgium

${ }^{7}$ Department of Obstetrics \& Gynecology, Imelda ziekenhuis, Imeldalaan 9, 2820 Bonheiden, Belgium

(C) The Author(s) 2021. Published by Oxford University Press on behalf of the Endocrine Society. All rights reserved. For permissions, please e-mail: journals.permissions@oup.com 
${ }^{8}$ Department of Endocrinology-Diabetology-Metabolism, Antwerp University Hospital, Drie Eikenstraat 655, 2650 Edegem, Belgium

${ }^{9}$ Department of Obstetrics \& Gynecology, Antwerp University Hospital, Drie Eikenstraat 655, 2650 Edegem, Belgium

${ }^{10}$ Department of Endocrinology, Kliniek St-Jan Brussel, Kruidtuinlaan 32, 1000 Brussel, Belgium ${ }^{11}$ Department of Obstetrics \& Gynecology, Kliniek St-Jan Brussel, Kruidtuinlaan 32, 1000 Brussel, Belgium

${ }^{12}$ Department of Endocrinology, AZ St Jan Brugge, Ruddershove 10, 8000 Brugge, Belgium

${ }^{13}$ Department of Obstetrics \& Gynecology, AZ St Jan Brugge, Ruddershove 10, 8000 Brugge, Belgium

${ }^{14}$ Center of Biostatics and Statistical bioinformatics, KU Leuven, Kapucijnenvoer 35 bloc $\mathrm{d}-$ box 7001 , 3000 Leuven, Belgium

The corresponding author:

Caro Minschart, Department of Endocrinology, UZ Gasthuisberg, KU Leuven, Herestraat 49, 3000 Leuven; caro.minschart@kuleuven.be; tel: +3216345134 
Grants/fellowships: This investigator-initiated study was funded by the Belgian National Lottery, the Fund of the Academic studies of UZ Leuven, and the Fund Yvonne and Jacques François-de Meurs of the King Boudewijn Foundation. $\mathrm{KB}$ and $\mathrm{RD}$ are the recipient of a 'Fundamenteel Klinisch Navorserschap FWO Vlaanderen'. CM has a PhD Fellowship Strategic Basic Research of the Research Foundation - Flanders (FWO).

Disclosure summary: Authors have no potential conflicts of interest relevant to the article. 


\section{Abstract}

Aims: To determine the impact of depressive symptoms on pregnancy outcomes and postpartum quality of life in women with gestational diabetes mellitus (GDM) and normal glucose tolerance (NGT).

Methods: 1843 women from a prospective cohort study received universal GDM screening with an oral glucose tolerance test (OGTT). The Center for Epidemiologic Studies - Depression questionnaire was completed before GDM diagnosis was communicated, and in GDM women in early postpartum. All participants completed the SF-36 health survey postpartum.

Results: Women who developed GDM $(231 ; 12.5 \%)$ had significantly more often depressive symptoms than NGT (1612; 87.5\%) women [21.3\% (48) vs. $15.1 \%$ (239), OR $1.52,95 \% \mathrm{Cl}(1.08-2.16)$, $\mathrm{p}=0.017]$. Compared to GDM women without depressive symptoms, depressed GDM women attended less often the postpartum OGTT [68.7\% (33) vs. 87.6\% (155), p=0.002], remained more often depressed [37.1\% (13) vs. 12.4\% (19), p<0.001] and had lower SF-36 scores postpartum. There were no significant differences in pregnancy outcomes between both groups. Rates of labor inductions were significantly higher in the NGT group with depressive symptoms compared to the non-depressed NGT group [31.7\% (75) vs. $24.7 \%$ (330), aOR 1.40, 95\% Cl (1.01-1.93), $p=0.041]$. NGT women with depressive symptoms had lower SF-36 scores $(p<0.001)$ postpartum compared to nondepressed NGT women.

Conclusions: Women with antenatal symptoms of depression develop more often GDM. GDM women with depressive symptoms remain more often depressed postpartum with lower quality of life. NGT women with depressive symptoms have higher rates of labor inductions and lower quality of life postpartum compared to non-depressed NGT women.

Keywords: antenatal depression; gestational diabetes mellitus; pregnancy outcomes; quality of life 


\section{Introduction}

The perinatal period is a time of increased susceptibility for the development of depression. Studies report a wide prevalence range of $15-65 \%$ of women experiencing antenatal depressive symptoms, which is independently associated with increased adverse pregnancy outcomes for both mother and child ${ }^{1,2}$. Moreover, antenatal depression is related to poor maternal-fetal attachment and women with antenatal depression are more inclined to suffer from postpartum depression too, which can have an extensive negative impact on the whole household in the long term ${ }^{3-7}$.

Depression is also a common mental disorder in women with gestational diabetes mellitus (GDM), with a median of $14.7 \%$ of women with GDM experiencing antenatal depressive symptoms ${ }^{8}$. GDM is defined as diabetes diagnosed in the second or third trimester of pregnancy, provided that overt diabetes early in pregnancy has been excluded ${ }^{9}$. GDM is one of the most frequent medical conditions during pregnancy and is associated with an increased risk of fetal and maternal complications such as preeclampsia and large-for-gestational age infants (LGA) ${ }^{10,11}$.

The relationship between depression and risk of type 2 diabetes was previously evaluated in a metaanalysis of 23 longitudinal studies, reporting a higher incidence of diabetes in depressed versus nondepressed subjects $(0.72 \%$ vs $0.47 \%$ yearly) with an adjusted pooled relative risk of $1.38(1.23-1.55)$

${ }^{12}$. Recently, a meta-analysis of 5 cohort studies has shown that having a depression before or during early pregnancy significantly increases the risk of developing GDM ${ }^{13}$. However, few studies have investigated the impact of having both antenatal depression and GDM on perinatal complications. In addition, more data are needed on the impact of depression in pregnancy on postpartum quality of life both in women with GDM and normal glucose tolerance (NGT). We aimed therefore to determine the prevalence of antenatal depressive symptoms and to investigate the impact of depressive symptoms on pregnancy outcomes and on postpartum quality of life both in women with GDM and NGT. 


\section{Patients and methods}

\section{Study design and setting}

This is a sub-analysis of the 'Belgian Diabetes in Pregnancy' (BEDIP-N) cohort. The BEDIP-N study was a multicentric prospective cohort study that has previously been described in detail ${ }^{14-17}$. The study protocol was approved by the Institutional Review Boards of all participating centers and all investigations have been carried out in accordance with the principles of the Declaration of Helsinki as revised in 2008. Participants provided informed consent before inclusion in the study and were enrolled between 6 and 14 weeks of pregnancy, when fasting plasma glucose (FPG) was measured. Women without impaired glucose tolerance or diabetes in early pregnancy, as defined by the ADA criteria, were universally screened for GDM between $24-28$ weeks of pregnancy and received both a non-fasting $50 \mathrm{~g}$ glucose challenge test (GCT) and a $75 \mathrm{~g}$ 2-hour oral glucose tolerance test (OGTT). Participants and health care providers were blinded to the result of the $\mathrm{GCT}$, so all participants received an OGTT irrespective of the GCT result. The diagnosis of GDM was based on the IADPSG criteria, now commonly referred to as the 2013 WHO criteria for GDM ${ }^{14,15}$. The ADA-recommended glycemic targets were used for the treatment of GDM ${ }^{18}$. Treatment with insulin was started if targets were not reached within two weeks after the start of lifestyle measures. Women with GDM were invited for an extra visit 6 to 16 weeks postpartum to receive a 75g OGTT. The ADA criteria were used to define diabetes and glucose intolerance [impaired fasting glycemia

(IFG) and/or impaired glucose tolerance (IGT) $]^{14,18}$.

\section{Study visits and measurements}

At first visit, baseline characteristics and the obstetrical history were collected ${ }^{14}$. At first visit and at the time of the OGTT, anthropometric measurements were obtained and self-administered questionnaires were completed ${ }^{14}$. The Center for Epidemiologic Studies - Depression (CES-D) 
questionnaire was completed at the time of the OGTT before the diagnosis of GDM was communicated, and for women with GDM also at the postpartum OGTT. This 20-item questionnaire is widely used in pregnant and postpartum women to assess symptoms of clinical depression over the past 7 days ${ }^{19}$. Total score on the CES-D questionnaire can range from 0 to 60 , with a score of 16 or higher being suggestive for clinical depression ${ }^{20}$. The SF-36 health survey was obtained at the postpartum OGTT from women with previous GDM and was sent by mail to all other participants three months postpartum. The SF-36 health survey is a set of generic, coherent, and easily administered quality-of-life measures that is validated for use in the maternity context ${ }^{21}$. Data from a questionnaire on lifestyle (completed in early pregnancy and at the time of the OGTT) that has been previously used to question servings per weeks of different important food categories and beverages, was used to create a diet score ${ }^{22}$. Higher consumption of fruit, vegetables, legumes, nuts, whole grains, dairy and fish, and lower consumption of red meat, sugared beverages, coffee, sauces, sweets and pastries, were assigned one point. Less healthy consumption was assigned 0 or 1 points. By summing up the points for all 14 food groups, the diet score could range from -12 to 15 . Data from this lifestyle questionnaire also generated a physical activity score, which was a composite variable of 3 items questioning daily walking, stair climbing and physical activity of more than moderate intensity. The total score for the physical activity composite variable could range from -1 to 5 with a higher score indicating a higher degree of physical activity.

To assess physical activity at the time of the OGTT, the international questionnaire on physical activity (IPAQ), validated for use in the Belgian population, was used ${ }^{14,23}$. Results of the IPAQ were reported in categories (low, moderate or high activity levels). Those who score 'high' engage in vigorous intensity activity on at least 3 days achieving a minimum total physical activity of at least 1500 metabolic equivalent of task (MET)-minutes a week, or 7 or more days of any combination of walking, moderate intensity or vigorous intensity activities achieving a minimum total physical activity of at least 3000 MET-minutes a week. Scoring a moderate level of physical activity are those who engage in 3 or more days of vigorous intensity activity of at least 20 minutes per day, or 5 or 
more days of moderate intensity activity and/or walking of at least 30 minutes per day, or 5 or more days of any combination of walking, moderate intensity or vigorous intensity activities achieving a minimum total physical activity of at least $600 \mathrm{MET}$-minutes a week. Those individuals who do not meet criteria for either moderate or high levels of physical activity are considered to have low physical activity. Blood pressure (BP) was measured twice at 5 min intervals using an automatic BP monitor ${ }^{14}$. Overweight was defined as a $\mathrm{BMI} \geq 25 \mathrm{~kg} / \mathrm{m}^{2}$ and obesity as a $\mathrm{BMI} \geq 30 \mathrm{~kg} / \mathrm{m}^{2}$ based on the $\mathrm{BMI}$ at first prenatal visit. At first visit, a fasting blood test was performed to measure FPG, insulin, lipid profile (total cholesterol, HDL and LDL cholesterol, triglycerides) and HbA1c. The homeostasis model assessment of insulin resistance (HOMA-IR) and beta-cell function (HOMA-B) was measured in early pregnancy ${ }^{24}$. At the time of the OGTT, a fasting lipid profile and HbA1c were measured. Glucose and insulin were measured fasting, at $30 \mathrm{~min}, 60 \mathrm{~min}$ and $120 \mathrm{~min}$. Insulin and glucose levels during the OGTT were used to calculate the Matsuda index, which is a measure of whole body insulin sensitivity ${ }^{25}$. Different indices of beta-cell function [HOMA-B, the insulinogenic index divided by HOMA-IR and the insulin secretion-sensitivity index-2 (ISSI-2)], were also measured at time of the OGTT ${ }^{14,24,26-28}$.

\section{Pregnancy and delivery outcome data}

The following pregnancy outcome data were collected: gestational age, preeclampsia (de novo BP $\geq 140 / 90 \mathrm{mmHg}>20$ weeks with proteinuria or signs of end-organ dysfunction), gestational hypertension (de novo BP $\geq 140 / 90 \mathrm{mmHg}>20$ weeks), type of labor and type of delivery with the indications, birth weight, macrosomia ( $>4 \mathrm{~kg}$ ), birth weight $\geq 4.5 \mathrm{~kg}$, large for gestational age (LGA) defined as birth weight $>90$ percentile according to standardized Flemish birth charts adjusted for sex of the baby and parity ${ }^{29}$, small for gestational age (SGA) defined as birth weight $<10$ percentile according to standardized Flemish birth charts adjusted for sex of the baby and parity ${ }^{29}$, preterm delivery (<37 completed weeks), 10min Apgar score, shoulder dystocia, neonatal respiratory distress 
syndrome, neonatal jaundice, congenital anomalies and admission on the neonatal intensive care unit $(\mathrm{NICU})^{14}$. A glycemic value $<2.2 \mathrm{mmol} / \mathrm{l}$, irrespective of the need for intravenous administration of glucose and admission on the NICU, was considered as a neonatal hypoglycemia across all centers. Admission to the NICU was decided by the neonatologist in line with normal routine in each center. Gestational weight gain was calculated in two different ways: as the difference in weight between first prenatal visit and delivery, and also as the difference between the self-reported prepregnancy weight and weight at delivery. Excessive total gestational weight gain was defined according to the 2009 Institute of Medicine (IOM) guidelines ${ }^{30}$.

\section{Statistical analysis}

Descriptive statistics were presented as frequencies and percentages for categorical variables and means with standard deviations or medians with interquartile range for continuous variables. The Chi-square test was used for comparing groups on categorical variables, or the Fisher exact test in case of low $(<5)$ cell frequencies. The Mann-Whitney $U$ test was used for comparing groups on continuous variables. Logistic regression and linear regression models were used to estimate the predictive value of depressive symptoms on binary and continuous pregnancy outcomes, with results presented as odds ratios or mean differences, respectively. Multivariable models were used to correct for confounding, and interaction terms were used to study the differential effect of depressive symptoms on adverse pregnancy outcomes according to GDM status. A logistic regression model was used to analyze the association between gestational weight gain as a continuous predictor and depression as a binary outcome. Cubic splines were used to model a nonlinear trend of weight change. A p-value $<0.05$ (two-tailed) was considered significant. Analyzes were performed by statistician A. Laenen by using SAS software. 


\section{Results}

\section{Prevalence of depressive symptoms in the BEDIP-N cohort}

2006 women were enrolled between 6 and 14 weeks of pregnancy. Of all participants, 1843 (91.9\%) were universally screened for GDM with a 75g OGTT between 24 and 28 weeks of pregnancy, with a GDM prevalence of $12.5 \%$ (231). Of all participants, 1823 (90.9\%) completed the CES-D questionnaire at $24-28$ weeks of pregnancy. For 1806 participants $(90.0 \%)$ both GDM status and depression status were known, of which 225 with GDM and 1581 with NGT. Of all responders, $16.1 \%$ (293) had symptoms of depression based on the CES-D questionnaire. Women with GDM experienced significantly more often depressive symptoms than NGT women [ $21.3 \%$ (48 out of 225) vs. $15.1 \%$ (239 out of 1581 ), OR $1.52,95 \% \mathrm{Cl}(1.08-2.16), \mathrm{p}=0.017$ ] at the time of the OGTT, before the diagnosis of GDM was communicated. After adjustment for confounding variables such as age, ethnicity, education, smoking before pregnancy and BMI at first prenatal visit, depression was no longer a significant risk factor for the development of GDM [adjusted OR 1.20, 95\% $\mathrm{Cl}$ (0.81-1.79), $\mathrm{p}=0.365]$. A history of depression, defined as the need for antidepressant medication, was significantly more often present in women with GDM compared to the NGT group [3.0\% (7) vs. $0.9 \%$ (15), $p=0.006$ ] (Table 1).

GDM subgroup: comparison between participants with and without symptoms of depression In the GDM subgroup with available CES-D scores (225), women experiencing depressive symptoms $(48,21.3 \%)$ were more often from an ethnic minority background (EMB) [29.2\% (14) vs. $15.4 \%(27)$, $p=0.030]$, smoked more often during pregnancy [12.5\% (6) vs. $4.0 \%(7), p=0.025]$, and had a higher BMI $\left(27.9 \pm 5.3 \mathrm{~kg} / \mathrm{m}^{2}\right.$ vs. $\left.26.3 \pm 5.3 \mathrm{~kg} / \mathrm{m}^{2}, \mathrm{p}=0.048\right)$ in early pregnancy compared to women 
without depressive symptoms $(177,78.7 \%)$. There was no significant difference in the proportion of women with a history of depression between both groups [4.2\% (2) vs. $2.4 \%(4), p=0.600]$ (Table 2).

At the time of the OGTT, women with GDM and depressive symptoms had significantly higher triglycerides and a lower diet score on the lifestyle questionnaire in comparison with women with GDM without depressive symptoms (Table 2). There were no significant differences in pregnancy outcomes between both groups (Table 2).

After pregnancy, GDM women with depressive symptoms attended less often the postpartum OGTT [68.7\% (33) vs. 87.6\% (155), p=0.002], experienced more often symptoms of depression [37.1\% (13) vs. $12.4 \%$ (19), $p<0.001$ ] and had lower SF-36 scores for almost all subscales compared to GDM women without depressive symptoms (Table 2).

\section{NGT subgroup: comparison between participants with and without symptoms of depression}

Compared to non-depressed NGT women (1342, 84.9\%), NGT women with depressive symptoms $(239,15.1 \%)$ had more often a history of depression [ $2.5 \%(6)$ vs. $0.7 \%(9), p=0.017]$, an EMB [18.8\% (45) vs. $6.1 \%(81), p<0.001]$, a lower education degree $(p<0.001)$, less often a paid job [79.8\% (189) vs. $94.0 \%$ (1258), $p<0.001$ ], smoked more often during pregnancy [5.4\% (13) vs. $2.9 \%(39), p=0.044]$ and had more often a first degree family history of diabetes [16.8\% (39) vs. $11.2 \%$ (146), p=0.015] (Table 3). At first prenatal visit, they had a higher BMI and were more insulin resistant (Table 3).

At 24-28 weeks of pregnancy, NGT women with symptoms of depression had higher 2-hour glucose values on the OGTT, were more insulin resistant, had higher fasting triglycerides, and were less physically active in their leisure time compared to non-depressed NGT women (Table 3).

The rates of preeclampsia and labor inductions were significantly higher in the depressed NGT group compared to the NGT group without symptoms of depression [respectively $3.4 \%$ (8) vs. $1.5 \%(20), p=$ 
0.046 and $31.7 \%$ (75) vs. $24.7 \%$ (330), p=0.023]. After adjustment for confounders such as EMB, education, smoking, BMI and glucose levels on the OGTT, only the rate of labor inductions remained significantly increased [aOR $1.40(95 \% \mathrm{Cl} 1.01-1.93), \mathrm{p}=0.041]$. NGT women with symptoms of depression had lower SF-36 scores $(p<0.001)$ postpartum for all subscales except for Health Transition compared to NGT women without symptoms of depression (Table 3).

\section{Antenatal symptoms of depression as a predictor for pregnancy outcomes in the total cohort}

Characteristics of depressed versus non-depressed women in the total cohort are presented in Table 4. Symptoms of depression during pregnancy were significantly associated with excessive gestational weight gain (Table 5). A U-shaped association was found between gestational weight gain and the probability of having symptoms of depression (Figure $1 \mathrm{~A}$ and B). No other significant differences were observed in perinatal outcomes between both groups (Table 5).

An interaction analysis between depression and GDM showed that the effect of depression on induction of labor was different depending on the presence of GDM ( $\mathrm{p}=0.036)$, with an OR of 0.63 (95\% CI $0.31-1.28, \mathrm{p}=0.204)$ for women with GDM and an OR of $1.41(95 \%$ CI $1.05-1.91, \mathrm{p}=0.024)$ for women without GDM.

\section{Discussion}

Depression is a common complication in the perinatal period and has been associated with an increased risk of adverse pregnancy outcomes ${ }^{1,2,31}$. Women with a history of depression may also be at increased risk of developing GDM ${ }^{13}$. Although GDM and antenatal depression have been studied frequently as independent risk factors for adverse perinatal outcomes, few studies have investigated the impact of having both antenatal depression and GDM on pregnancy outcomes. In order to potentially reduce perinatal complications in this high-risk population, the relationship between the 
two conditions needs to be better understood. In addition, more data are needed on the impact of depression in pregnancy on postpartum quality of life both in women with GDM and NGT. We evaluated therefore the impact of antenatal symptoms of depression on pregnancy outcomes and on postpartum quality of life in women with GDM and NGT. We showed that $16.1 \%$ of women experienced depressive symptoms at 24-28 weeks of gestation. We found much higher rates of depression than two recent studies from the United States, respectively reporting depression in 9.8\% of women in the second trimester and a clinically identified depression during pregnancy in $6.9 \%$ of women ${ }^{4,32}$. The large variation in reported prevalence rates of antenatal depression is probably related to differences in the definition of depression used, the population studied, and the period over which the prevalence is being assessed.

Conflicting evidence exists regarding the association between antenatal depression and GDM. A Canadian registry study of deliveries included women with major depression and women without mental illness and found no increased prevalence of GDM in depressed women ${ }^{33}$. Moreover, a recent systematic review investigating the relationship between GDM and common mental disorders (CMD) such as anxiety and depression in a large UK birth cohort, found no evidence for an association between CMD prior to pregnancy and GDM (adjusted RR 0.96; 95\% $\mathrm{Cl} 0.80-1.15$ ) or between GDM and CMD during pregnancy (adjusted OR 0.91; 95\% $\mathrm{Cl} 0.73-1.12$ ). ${ }^{34}$. In contrast, other studies report modest to strong associations between both conditions ${ }^{13,32,35}$. We found that women with antenatal depressive symptoms, identified as a CES-D score $\geq 16$ at $24-28$ weeks of gestation, developed more often GDM compared to non-depressed women. Since the symptoms of depression were assessed before the diagnosis of GDM was communicated, the diagnosis of GDM did not have an impact on the depression assessment. Our data suggest therefore that women with antenatal symptoms of depression are at increased risk of developing GDM. However, depression was no longer a significant risk factor for developing GDM after adjustment for confounders such as age, ethnicity, education, smoking before pregnancy and BMI at first prenatal visit. The higher prevalence of symptoms of depression in women with GDM might therefore be related to a less 
healthy lifestyle in women with depression. Our study demonstrated that depression is an independent risk factor for excessive gestational weight gain in the total cohort (GDM and NGT combined). We measured gestational weight gain based on measured weight in early pregnancy and by using the self-reported prepregnancy weight. While the first method might underestimate total gestational weight gain in women with a large amount of weight gain in early pregnancy prior to enrollment in the study, prepregnancy weight is subject to recall bias since this was self-reported. Moreover, fewer data were missing for the registered weight at first visit compared to the selfreported prepregnancy weight. We found a U-shaped association between gestational weight gain and the probability of having depressive symptoms, indicating that both women with weight loss and a large amount of weight gain during pregnancy have a higher probability of experiencing symptoms of depression. In addition, our study showed that compared to non-depressed women with GDM, women with GDM and depressive symptoms had a less healthy diet at 24-28 weeks of pregnancy, and that NGT women with depressive symptoms were less physically active in their leisure time at 24-28 weeks of pregnancy compared to non-depressed NGT women.

In our cohort, GDM women with symptoms of depression had similar pregnancy outcomes compared to GDM women without symptoms of depression. In contrast, a Malaysian study showed that neonatal respiratory distress at delivery was associated with the presence of depression symptoms in GDM mothers (aOR 3.87, 95\% Cl 1.32-11.35) ${ }^{36}$. Recently, another retrospective cohort study demonstrated that women with a diagnosis of GDM and a concurrent diagnosis of antenatal depression were more likely to have adverse perinatal outcomes such as preeclampsia and preterm birth, as compared to non-depressed GDM controls ${ }^{8}$. However, antenatal depression was identified by ICD-9 codes in the discharge abstracts in this study, thereby possibly selecting women with more severe symptoms of depression compared to our study cohort. 
More data are needed on the combined effect of having both antenatal depression and GDM on postpartum mental health and quality of life. Our study showed that depressed women with GDM attended less often the postpartum OGTT and experienced more often symptoms of depression after delivery with lower quality of life scores as compared to non-depressed women with GDM. Screening for symptoms of depression during pregnancy in women with GDM could therefore help to improve mental health after pregnancy through a timely intervention. This is also important to improve compliance with postpartum screening for glucose intolerance and stimulate a healthy lifestyle postpartum to prevent the development of type 2 diabetes later in life.

Our study showed similar pregnancy outcomes after adjustment for confounders between depressed and non-depressed NGT women except for significantly higher rates of labor induction in NGT women with depressive symptoms. Moreover, we showed that the effect of depression on induction of labor was different depending on the presence of GDM. In contrast, a recent systematic review showed that the risk of low birth weight and preterm birth was about 1.40 times higher among infants born from depressed mothers ${ }^{1}$. The differences with our study could be related to differences in the use of the diagnostic tool for depression and timing of the diagnosis. Our study showed that depressed NGT women engaged less in leisure-time physical activity than nondepressed NGT women. These observations highlight the importance of interventions to improve maternal mental health during pregnancy to reduce the negative impact of depression on lifestyle behaviors and postpartum quality of life.

Moreover, we demonstrated that NGT women with depressive symptoms experienced lower quality of life three months postpartum compared to NGT women without symptoms of depression. This finding implies that the consequences of antenatal depression are not limited to pregnancy and delivery itself but may also have substantial consequences after childbirth. Previous research has demonstrated significant correlations between postpartum depression and postpartum quality of life ${ }^{37,38}$. These findings, together with the observations from our study, suggest that health care 
providers should offer individualized care for the prevention and treatment of depression both during and after pregnancy to improve postpartum quality of life.

This study has several strengths. We provide data of a large prospective cohort with extensive information on clinical and biochemical characteristics, pregnancy outcomes and postpartum quality of life. Validated questionnaires were used for the assessment of symptoms of depression and quality of life. A limitation of the study is the cross-sectional assessment of depressive symptoms, making it impossible to investigate a longitudinal relationship between depression and GDM. In addition, information on a history of depression before completing the antenatal CES-D questionnaire was limited.

In conclusion, we showed that women with antenatal symptoms of depression developed more often GDM and that GDM women with depressive symptoms remained more often depressed postpartum with lower quality of life. NGT women with depressive symptoms had higher rates of labor inductions and lower quality of life postpartum compared to NGT women without symptoms of depression. 


\section{Acknowledgements}

KB and RD are the recipient of a 'Fundamenteel Klinisch Navorserschap FWO Vlaanderen'. Caro Minschart has a PhD Fellowship Strategic Basic Research of the Research Foundation - Flanders (FWO). We thank Dr. Inge Beckstedde from the UZA site and Dr. Sylva Van Imschoot from the AZ St Jan Brugge site for their help with the recruitment and study assessments. We thank the research assistants, paramedics and physicians of all participating centers for their support and we thank all women who participated in the study.

\section{Funding}

This investigator-initiated study was funded by the Belgian National Lottery, the Fund of the Academic studies of UZ Leuven, and the Fund Yvonne and Jacques François-de Meurs of the King Boudewijn Foundation.

\section{Duality of interest}

No potential conflicts of interest relevant to the article were reported.

\section{Author contributions}

KB, PVC and CM (Chantal Mathieu) conceived the project. CM (Carolien Moyson), KDW and AE prepared the data and AL did the statistical analysis. CM (Caro Minschart) did the literature review. CM (Caro Minschart) and KB wrote the first draft of the manuscript. All authors contributed to the study design, including data collection, data interpretation and manuscript revision. The 
corresponding author $\mathrm{CM}$ had full access to all the data in the study and had final responsibility for the contents of the article and the decision to submit for publication.

\section{Data availability}

All data generated or analyzed during this study are included in this published article 


\section{References}

1. Dadi AF, Miller ER, Bisetegn TA, Mwanri L. Global burden of antenatal depression and its association with adverse birth outcomes: an umbrella review. BMC Public Health. 2020;20(173):1-16.

2. Byrn MA, Penckofer S. Antenatal Depression and Gestational Diabetes: A Review of Maternaland Fetal Outcomes. Nurs Womens Health. 2013;17(1):22-33. doi:10.1111/1751486X.12003

3. Choi SK, Park YG, Park IY, Ko HS, Shin JC. Impact of antenatal depression on perinatal outcomes and postpartum depression in Korean women. J Res Med Sci. 2014;19(9):807-812.

4. Dietz P, Williams SB, Callaghan W, Bachman D, Whitlock E, Hornbrook M. Clinically Identified Maternal Depression Before, During, and After Pregnancies Ending in Live Births. Am J Psychiatry. 2007;164:1515-1520.

5. Heron J, O'Connor TG, Evans J, Golding J, Glover V. The course of anxiety and depression through pregnancy and the postpartum in a community sample. J Affect Disord. 2004;80(1):65-73. doi:10.1016/j.jad.2003.08.004

6. Rubertsson C, Waldenström U, Wickberg B, Rådestad I, Hildingsson I. Depressive mood in early pregnancy and postpartum: Prevalence and women at risk in a national Swedish sample. J Reprod Infant Psychol. 2005;23(2):155-166. doi:10.1080/02646830500129289

7. Lindgren K. Relationships among maternal-fetal attachment, prenatal depression, and health practices in pregnancy. Res Nurs Heal. 2001;24(3):203-217. doi:10.1002/nur.1023

8. Packer CH, Pilliod RA, Chatroux LR, Caughey AB, Valent AM. Increased rates of adverse 
perinatal outcomes in women with gestational diabetes and depression. J Matern Neonatal Med. 2019:1-5. doi:10.1080/14767058.2019.1701647

9. American Diabetes Association. Standards of Medical Care in Diabetes - 2017. Diabetes Care. 2017;40(Suppl. 1):S11-S24.

10. Crowther CA, Hiller JE, Moss JR, McPhee AJ, Jeffries WS, Robinson JS. Effect of treatment of gestational diabetes mellitus on pregnancy outcomes. N Engl J Med. 2005;352(24):24772486. doi:10.1056/NEJMoa042973

11. Landon $\mathrm{MB}$, Spong $\mathrm{CY}$, Thom $\mathrm{E}$, et al. A multicenter, randomized trial of treatment for mild gestational diabetes. N Engl J Med. 2009;361(14):1339-1348. doi:10.1056/NEJMoa0902430

12. Rotella F, Mannucci E. Depression as a Risk Factor for Diabetes. J Clin Psychiatry. 2013;74(01):31-37. doi:10.4088/JCP.12r07922

13. Arafa A, Dong J-Y. Depression and risk of gestational diabetes: A meta-analysis of cohort studies. Diabetes Res Clin Pract. 2019;156(107826). doi:10.1016/j.diabres.2019.107826

14. Benhalima K, Van Crombrugge P, Verhaeghe J, et al. The Belgian Diabetes in Pregnancy Study ( BEDIP-N ), a multi-centric prospective cohort study on screening for diabetes in pregnancy and gestational diabetes : methodology and design. BMC Pregnancy Childbirth. 2014;14(226):1-13.

15. Benhalima K, Van Crombrugge $P$, Moyson $C$, et al. The sensitivity and specificity of the glucose challenge test in a universal two-step screening strategy for gestational diabetes mellitus using the 2013 World Health Organization criteria. Diabetes Care. 2018;41(7):e111-e112. doi:10.2337/DC18-0556

16. Benhalima K, Van Crombrugge $\mathrm{P}$, Moyson $\mathrm{C}$, et al. A modified two-step screening strategy for gestational diabetes mellitus based on the 2013 who criteria by combining the glucose 
challenge test and clinical risk factors. J Clin Med. 2018;7(10):351.

17. Benhalima $\mathrm{K}$, Van Crombrugge $\mathrm{P}$, Moyson $\mathrm{C}$, et al. Characteristics and pregnancy outcomes across gestational diabetes mellitus subtypes based on insulin resistance. Diabetologia. 2019;62:2118-2128. doi:10.1007/s00125-019-4961-7

18. American Diabetes Association. Standards of medical care in diabetes-2013. Diabetes Care. 2013;36:S11-66. doi:10.2337/dc13-S011

19. Dalfrà MG, Nicolucci A, Bisson T, Bonsembiante B, Lapolla A. Quality of life in pregnancy and post-partum: a study in diabetic patients. Qual Life Res. 2012;21:291-298. doi:10.1007/s11136-011-9940-5

20. Radloff LS. The CES-D Scale: A Self-Report Depression Scale for Research in the General Population. Appl Psychol Meas. 1977;1(3):385-401.

21. Petrou S, Morrell J, Spiby H. Assessing the empirical validity of alternative multi-attribute utility measures in the maternity context. Health Qual Life Outcomes. 2009;7:40-52. doi:10.1186/1477-7525-7-40

22. Durán A, Martín P, Runkle l, et al. Benefits of self-monitoring blood glucose in the management of new-onset Type 2 diabetes mellitus: The St carlos study, a prospective randomized clinic-based interventional study with parallel groups. J Diabetes. 2010;2(3):203211. doi:10.1111/j.1753-0407.2010.00081.x

23. Harrison $\mathrm{C}$, Thompson $\mathrm{R}$, Teede $\mathrm{H}$, Lombard $\mathrm{C}$. Measuring physical activity during pregnancy. Int J Behav Nutr Phys Act. 2011;8:19. doi:10.1186/1479-5868-8-19

24. Matthews DR, Hosker JP, Rudenski AS, Naylor BA, Treacher DF, Turner RC. Homeostasis model assessment: insulin resistance and $\beta$-cell function from fasting plasma glucose and insulin concentrations in man. Diabetologia. 1985;28(7):412-419. doi:10.1007/BF00280883 
25. Matsuda M, DeFronzo RA. Insulin sensitivity indices obtained from oral glucose tolerance testing: Comparison with the euglycemic insulin clamp. Diabetes Care. 1999;22(9):1462-1470. doi:10.2337/diacare.22.9.1462

26. Kahn SE. The relative contributions of insulin resistance and beta-cell dysfunction to the pathophysiology of Type 2 diabetes. Diabetologia. 2003;46(1):3-19. doi:10.1007/s00125-0021009-0

27. Kirwan JP, Huston-Presley L, Kalhan SC, Catalano PM. Clinically useful estimates of insulin sensitivity during pregnancy - Validation studies in women with normal glucose tolerance and gestational diabetes mellitus. Diabetes Care. 2001;24(9):1602-1607. doi:10.2337/diacare.24.9.1602

28. Retnakaran R, Qi Y, Goran MI, Hamilton JK. Evaluation of proposed oral disposition index measures in relation to the actual disposition index. Diabet Med. 2009;26(12):1198-1203. doi:10.1111/j.1464-5491.2009.02841.x

29. Devlieger H, Martens G, Bekaert A, Eeckels R. Standaarden van geboortegewicht-voorzwangerschapsduur voor de vlaamse boreling. Tijdschr Geneeskd. 2000;56(1):1-14.

30. IOM (Institute of Medicine) and NRC (National Research Council). Weight Gain during Pregnancy: Reexamining the Guidelines. Washington, DC; 2009.

31. Khanghah AG, Khalesi ZB, Hassanzadeh R. The importance of depression during pregnancy. JBRA Assist Reprod. 2020;00(0):00-00. doi:10.5935/1518-0557.20200010

32. Hinkle SN, Buck Louis GM, Rawal S, Zhu Y, Albert PS, Zhang C. A longitudinal study of depression and gestational diabetes in pregnancy and the postpartum period. Diabetologia. 2016;59(12):2594-2602. doi:10.1007/s00125-016-4086-1

33. Mei-Dan E, Ray JG, Vigod SN. Perinatal outcomes among women with bipolar disorder: A 
population-based cohort study. Am J Obstet Gynecol. 2015;212(3):367.e1-367.e8.

doi:10.1016/j.ajog.2014.10.020

34. Wilson CA, Santorelli G, Dickerson J, et al. Is there an association between anxiety and depression prior to and during pregnancy and gestational diabetes? An analysis of the Born in Bradford cohort. J Affect Disord. 2020;276:345-350.

35. Morrison C, Mccook JG, Bailey BA. First trimester depression scores predict development of gestational diabetes mellitus in pregnant rural Appalachian women. J Psychosom Obstet Gynecol. 2016;37(1):21-25. doi:10.3109/0167482X.2015.1106473

36. Lee KW, Ching SM, Hoo FK. Neonatal outcomes and its association among gestational diabetes mellitus with and without depression, anxiety and stress symptoms in Malaysia: A cross-sectional study. Midwifery. 2020;81(102586). doi:10.1016/j.midw.2019.102586

37. Zubaran C, Foresti K. Investigating quality of life and depressive symptoms in the postpartum period. Women and Birth. 2011;24(1):10-16. doi:10.1016/j.wombi.2010.05.002

38. Papamarkou M, Sarafis $P$, Kaite $C P$, Malliarou M, Tsounis A, Niakas D. Investigation of the association between quality of life and depressive symptoms during postpartum period: a correlational study. BMC Womens Health. 2017;17(115):1-9. doi:10.1186/s12905-017-0473-0 
Table 1: Lifestyle characteristics in women with GDM compared to women with NGT

\begin{tabular}{|c|c|c|c|}
\hline & $\begin{array}{l}\text { GDM } \\
N=231 \\
(12.5 \%)\end{array}$ & $\begin{array}{l}\text { NGT } \\
\begin{array}{l}\text { N= 1612 } \\
(87.5 \%)\end{array}\end{array}$ & p-value \\
\hline \multicolumn{4}{|l|}{ General characteristics } \\
\hline \% Smoking before pregnancy & $35.4(81)$ & $28.5(457)$ & 0.032 \\
\hline \% Smoking during pregnancy & $5.7(13)$ & $3.2(52)$ & 0.063 \\
\hline$\%$ History of depression & $3.0(7)$ & $0.9(15)$ & 0.006 \\
\hline \multicolumn{4}{|l|}{ 6-14 weeks of pregnancy } \\
\hline$\%$ Overweight & $29.1(67)$ & $24.8(398)$ & $<0.001$ \\
\hline$\%$ Obesity & $23.5(54)$ & $11.0(177)$ & $<0.001$ \\
\hline$\%$ Waist $\geq 80 \mathrm{~cm}$ & $81.6(178)$ & $74.1(1144)$ & $<0.001$ \\
\hline $\begin{array}{l}\text { Lifestyle score: } \\
\text { Physical activity } \\
\text { Diet }\end{array}$ & $\begin{array}{l}1.0(0.0-2.0) \\
2.0(0.0-4.0)\end{array}$ & $\begin{array}{l}1.0(0.0-2.0) \\
2.0(0.0-4.0)\end{array}$ & $\begin{array}{l}0.222 \\
0.747\end{array}$ \\
\hline \multicolumn{4}{|l|}{ 24-28 weeks of pregnancy } \\
\hline \% Overweight & $40.1(89)$ & 40.1 (629) & $<0.001$ \\
\hline$\%$ Obesity & $36.0(80)$ & $21.1(332)$ & $<0.001$ \\
\hline $\begin{array}{l}\text { Lifestyle score: } \\
\text { Physical activity } \\
\text { Diet }\end{array}$ & $\begin{array}{l}1.0(0.0-2.0) \\
2.0(-1.0-4.0)\end{array}$ & $\begin{array}{l}1.0(0.0-2.0) \\
2.0(0.0-4.0)\end{array}$ & $\begin{array}{l}0.460 \\
0.457\end{array}$ \\
\hline \multicolumn{4}{|l|}{ IPAQ } \\
\hline Total work & $0.0(0.0-396.0)$ & $0.0(0.0-600.0)$ & 0.342 \\
\hline Total transport & $330.0(93.0-825.0)$ & $330.0(99.0-792.0)$ & 0.895 \\
\hline Total garden and household & $660.0(180.0-1560.0)$ & $720.0(270.0-1620.0)$ & 0.416 \\
\hline Total leisure & $148.5(0.0-556.0)$ & $198.0(0.0-495.0)$ & 0.298 \\
\hline Total walking & $528.0(148.5-1155.0)$ & $528.0(198.0-1188.0)$ & 0.790 \\
\hline Total moderate & $1200.0(360.0-2490.0)$ & $1260.0(540.0-2640.0)$ & 0.125 \\
\hline Total Vigorous & $0.0(0.0-0.0)$ & $0.0(0.0-0.0)$ & 0.326 \\
\hline Total overall & $2374.0(1105.5-3828.0)$ & $2208.0(1140.0-4386.0)$ & 0.482 \\
\hline $\begin{array}{l}\text { METs category: } \\
\text { Low } \\
\text { Moderate } \\
\text { High }\end{array}$ & $\begin{array}{l}19.5(43) \\
43.4(96) \\
37.1(82)\end{array}$ & $\begin{array}{l}16.3(252) \\
47.2(731) \\
36.5(566)\end{array}$ & 0.411 \\
\hline $\begin{array}{l}\% \text { Clinical depression ( } \geq 16 / 20 \text { on } \\
\text { CES-D questionnaire) }\end{array}$ & $21.3(48)$ & $15.1(239)$ & 0.017 \\
\hline \multicolumn{4}{|l|}{ Postpartum } \\
\hline \multicolumn{4}{|l|}{ SF-36 } \\
\hline Physical functioning & $90.0(75.0-100.0)$ & $90.0(85.0-100.0)$ & 0.010 \\
\hline Role physical & $87.5(62.5-100.0)$ & $87.5(62.5-100.0)$ & 0.812 \\
\hline Role Emotional & $100.0(75.0-100.0)$ & $100.0(66.7-100.0)$ & 0.716 \\
\hline Energy & $62.5(50.0-75.0)$ & $62.5(50.0-75.0)$ & 0.125 \\
\hline
\end{tabular}




\begin{tabular}{|l|l|l|l|}
\hline Emotional Wellbeing & $70.0(65.0-75.0)$ & $70.0(65.0-75.0)$ & 0.762 \\
\hline Social functioning & $87.5(75.0-100.0)$ & $87.5(75.0-100.0)$ & 0.313 \\
\hline Pain & $90.0(77.5-100.0)$ & $90.0(77.5-100.0)$ & 0.554 \\
\hline General Health & $75.0(60.0-85.0)$ & $75.0(65.0-85.0)$ & 0.038 \\
\hline Health Transition & $50.0(50.0-50.0)$ & $50.0(50.0-50.0)$ & 0.131 \\
\hline
\end{tabular}

GDM: gestational diabetes mellitus; NGT: normal glucose tolerance; IPAQ: International Physical Activity Questionnaire; CES-D: Center for Epidemiologic Studies - Depression; SF-36: 36-Item Short Form Health Survey; Lifestyle score: physical activity subscale ranges from -1 to +5 and diet subscale ranges from -12 to +15; Categorical variables are presented as frequencies $\%(n)$; continuous variables are presented as mean \pm SD if normally distributed and as median \pm IQR if not normally distributed; overweight: BMI $\geq 25-29.9 \mathrm{Kg} / \mathrm{m}^{2}$; obesity: $\mathrm{BMI} \geq 30 \mathrm{Kg} / \mathrm{m}^{2}$; Differences are considered significant at $\mathrm{p}$-value $<0.05$; 
Table 2: Comparison of characteristics and pregnancy outcomes of women with GDM and depression versus women with GDM without depression

\begin{tabular}{|c|c|c|c|}
\hline & $\begin{array}{l}\text { GDM with depression } \\
\mathrm{N}=48 \\
(21.3 \%)\end{array}$ & $\begin{array}{l}\text { GDM without depression } \\
\mathrm{N}=177 \\
(\mathbf{7 8 . 7 \% )}\end{array}$ & p-value \\
\hline \multicolumn{4}{|l|}{ General characteristics } \\
\hline Mean age (years) & $31.4 \pm 5.5$ & $32.3 \pm 4.4$ & 0.205 \\
\hline \% Non-Caucasian & $29.2(14)$ & $15.4(27)$ & 0.030 \\
\hline \% Multiparity & $50.0(24)$ & $52.5(93)$ & 0.755 \\
\hline $\begin{array}{l}\text { \% Highest Education: } \\
\text { Primary school } \\
\text { Till } 15 \text { years } \\
\text { High school } \\
\text { Bachelor } \\
\text { Master }\end{array}$ & $\begin{array}{l}6.8(3) \\
6.8(3) \\
22.7(10) \\
36.4(16) \\
27.3(12)\end{array}$ & $\begin{array}{l}1.7(3) \\
4.1(7) \\
21.1(36) \\
36.3(62) \\
36.8(63)\end{array}$ & 0.315 \\
\hline \% Paid job & $80.8(38)$ & $90.8(158)$ & 0.056 \\
\hline \% Smoking during pregnancy & $12.5(6)$ & $4.0(7)$ & 0.025 \\
\hline $\begin{array}{l}\% \text { First degree family history of } \\
\text { diabetes }\end{array}$ & $17.0(8)$ & $18.7(32)$ & 0.791 \\
\hline$\%$ History of depression & $4.2(2)$ & $2.3(4)$ & 0.610 \\
\hline \multicolumn{4}{|l|}{ 6-14 weeks of pregnancy } \\
\hline $\begin{array}{l}\text { BMI at first prenatal visit } \\
\left(\mathrm{Kg} / \mathrm{m}^{2}\right)\end{array}$ & $27.9 \pm 5.3$ & $26.3 \pm 5.3$ & 0.048 \\
\hline HOMA-IR & $12.5(7.8-18.3)$ & $10.7(7.9-16.8)$ & 0.488 \\
\hline $\begin{array}{l}\text { Fasting Total cholesterol } \\
(\mathrm{mmol} / \mathrm{l})\end{array}$ & $4.6(4.1-5.6)$ & $4.8(4.2-5.4)$ & 0.956 \\
\hline Fasting HDL (mmol/l) & $1.8(1.5-1.9)$ & $1.8(1.5-2.0)$ & 0.229 \\
\hline Fasting LDL (mmol/l) & $2.5(1.9-3.1)$ & $2.4(2.1-2.9)$ & 0.615 \\
\hline Fasting TG (mmol/l) & $1.2(1.0-1.6)$ & $1.1(0.9-1.5)$ & 0.227 \\
\hline \multicolumn{4}{|l|}{ 24-28 weeks of pregnancy } \\
\hline Fasting glycemia $(\mathrm{mmol} / \mathrm{l})$ & $4.8(4.5-5.3)$ & $4.7(4.3-5.1)$ & 0.057 \\
\hline 1-hour glucose OGTT (mmol/l) & $9.1(8.4-10.2)$ & $9.6(8.5-10.4)$ & 0.370 \\
\hline 2-hour glucose OGTT (mmol/l) & $8.7(7.2-9.0)$ & $8.6(7.7-9.3)$ & 0.589 \\
\hline $\mathrm{HbA1c}(\mathrm{mmol} / \mathrm{mol}, \%)$ & $\begin{array}{l}32.2(30.1-35.5) \\
5.1(4.9-5.4)\end{array}$ & $\begin{array}{l}32.2(30.1-33.3) \\
5.1(4.9-5.2)\end{array}$ & 0.063 \\
\hline HOMA-IR & $21.3(15.5-29.9)$ & $16.7(11.2-26.2)$ & 0.055 \\
\hline $\begin{array}{l}\text { Fasting Total Cholesterol } \\
(\mathrm{mmol} / \mathrm{l})\end{array}$ & $6.0(5.5-7.0)$ & $6.4(5.6-7.0)$ & 0.298 \\
\hline Fasting HDL (mmol/l) & $1.8(1.5-2.1)$ & $1.9(1.7-2.2)$ & 0.039 \\
\hline Fasting LDL (mmol/l) & $3.2(2.7-3.9)$ & $3.5(2.8-4.1)$ & 0.156 \\
\hline Fasting TG (mmol/l) & $2.2(1.9-2.9)$ & $2.0(1.6-2.5)$ & 0.023 \\
\hline $\begin{array}{l}\text { Lifestyle score: } \\
\text { Physical activity } \\
\text { Diet }\end{array}$ & $\begin{array}{l}1.0(0.0-2.0) \\
1.0(-2.0-3.0)\end{array}$ & $\begin{array}{l}1.0(0.0-2.0) \\
2.0(0.0-4.0)\end{array}$ & $\begin{array}{l}0.914 \\
\mathbf{0 . 0 2 7}\end{array}$ \\
\hline
\end{tabular}




\begin{tabular}{|c|c|c|c|}
\hline $\begin{array}{l}\text { METs category: } \\
\text { \% Low } \\
\% \text { Moderate } \\
\% \text { High }\end{array}$ & $\begin{array}{l}25.5(12) \\
44.7(21) \\
29.8(14)\end{array}$ & $\begin{array}{l}18.0(31) \\
42.4(73) \\
39.5(68)\end{array}$ & 0.361 \\
\hline \multicolumn{4}{|l|}{ Delivery } \\
\hline $\begin{array}{l}\text { \% excessive GWG (first visit - } \\
\text { delivery) }^{\mathrm{b}}\end{array}$ & $18.4(7)$ & $18.5(29)$ & 0.865 \\
\hline $\begin{array}{l}\text { \% excessive GWG } \\
\text { (prepregnancy - delivery) }^{c}\end{array}$ & $32.4(12)$ & $24.8(36)$ & 0.630 \\
\hline Gestational age (weeks) & $38.8 \pm 1.4$ & $38.9 \pm 1.5$ & 0.617 \\
\hline \% Preeclampsia & $0.0(0)$ & $1.7(3)$ & 0.374 \\
\hline \% Gestational hypertension & $6.5(3)$ & $3.4(6)$ & 0.336 \\
\hline \% Preterm delivery & $8.7(4)$ & $7.3(13)$ & 0.758 \\
\hline \% Induction labor & $28.3(13)$ & $38.4(68)$ & 0.202 \\
\hline$\%$ Forceps or vacuum & $13.0(6)$ & $11.9(21)$ & 0.827 \\
\hline \% Cesarean sections (total) & $34.8(16)$ & $24.9(44)$ & 0.176 \\
\hline$\%$ Macrosomia $(>4 \mathrm{Kg})^{\mathrm{a}}$ & $6.7(3)$ & $7.3(13)$ & 0.875 \\
\hline$\%$ LGA & $15.2(7)$ & $11.9(21)$ & 0.541 \\
\hline$\% \mathrm{SGA}$ & $2.2(1)$ & $5.6(10)$ & 0.332 \\
\hline$\%$ Apgar $10 \mathrm{~min}<7$ & $0.0(0)$ & $0.6(1)$ & 0.608 \\
\hline \%Shoulder dystocia & $2.2(1)$ & $0.6(1)$ & 0.302 \\
\hline$\%$ Congenital anomaly & $4.4(2)$ & $5.1(9)$ & 0.860 \\
\hline $\begin{array}{l}\text { \% Respiratory Distress } \\
\text { syndrome }\end{array}$ & $0.0(0)$ & $1.1(2)$ & 0.469 \\
\hline $\begin{array}{l}\% \text { Neonatal hypoglycemia } \\
<2.2 \mathrm{mmol} / \mathrm{l}\end{array}$ & $7.9(3)$ & $15.4(25)$ & 0.303 \\
\hline Neonatal jaundice & $11.5(3)$ & $16.8(21)$ & 0.768 \\
\hline \% NICU admission & $10.9(5)$ & $15.2(27)$ & 0.450 \\
\hline Days on NICU & $5.8 \pm 4.3$ & $7.2 \pm 8.5$ & 0.798 \\
\hline \multicolumn{4}{|l|}{ Postpartum } \\
\hline$\%$ present at OGTT & $68.7(33)$ & $87.6(155)$ & 0.002 \\
\hline $\begin{array}{l}\text { \% glucose intolerance } \\
\text { IFG } \\
\text { IGT } \\
\text { IFG+IGT }\end{array}$ & $\begin{array}{l}18.2(6) \\
6.1(2) \\
6.1(2) \\
6.1(2)\end{array}$ & $\begin{array}{l}18.7(29) \\
7.1(11) \\
11.0(17) \\
0.6(1)\end{array}$ & $\begin{array}{l}0.944 \\
0.128\end{array}$ \\
\hline \% breastfeeding & $85.3(29)$ & $82.1(124)$ & 0.658 \\
\hline $\begin{array}{l}\text { Lifestyle score: } \\
\text { Physical activity } \\
\text { Diet }\end{array}$ & $\begin{array}{l}1.0(0.0-3.0) \\
3.0(0.0-5.0)\end{array}$ & $\begin{array}{l}1.0(0.0-2.0) \\
2.0(0.0-5.0)\end{array}$ & $\begin{array}{l}0.514 \\
0.636\end{array}$ \\
\hline \multicolumn{4}{|l|}{ SF-36 } \\
\hline Physical functioning & $80.0(65.0-95.0)$ & $90.0(80.0-100.0)$ & 0.002 \\
\hline Role physical & $75.0(56.2-100.0)$ & $87.5(68.7-100.0)$ & 0.083 \\
\hline Role Emotional & $83.3(50.0-100.0)$ & $100.0(75.0-100.0)$ & 0.038 \\
\hline Energy & $50.0(43.7-68.7)$ & $64.6(56.2-75.0)$ & $<0.001$ \\
\hline Emotional well-being & $70.0(60.0-75.0)$ & $70.0(65.0-75.0)$ & 0.017 \\
\hline Social functioning & $87.5(62.5-100.0)$ & $100.0(75.0-100.0)$ & 0.003 \\
\hline Pain & $80.0(67.5-100.0)$ & $90.0(77.5-100.0)$ & 0.039 \\
\hline General Health & $65.0(45.0-80.0)$ & $75.0(65.0-85.0)$ & 0.007 \\
\hline Health Transition & $50.0(25.0-75.0)$ & $50.0(50.0-50.0)$ & 0.369 \\
\hline $\begin{array}{l}\text { METs category: } \\
\text { \% Low } \\
\text { \% Moderate } \\
\text { \% High }\end{array}$ & $\begin{array}{l}6.9(2) \\
41.4(12) \\
51.7(15)\end{array}$ & $\begin{array}{l}12.3(18) \\
50.7(74) \\
37.0(54)\end{array}$ & 0.304 \\
\hline $\begin{array}{l}\% \text { Clinical depression } \\
(\geq 16 \text { on CES-D questionnaire) }\end{array}$ & $37.1(13)$ & $12.4(19)$ & $<0.001$ \\
\hline
\end{tabular}


GDM: gestational diabetes mellitus; OR: odds ratio; $\mathrm{Cl}$ : confidence interval; BMI: Body Mass Index; OGTT: oral glucose tolerance test; HDL: high-density lipoprotein; LDL: low-density-lipoprotein; TG: triglycerides; MET: metabolic equivalent of task; GWG: gestational weight gain; LGA: large-for-gestational age infant; SGA: smallfor-gestational age infant; NICU: neonatal intensive care unit; IFG: impaired fasting glycemia; IGT: impaired glucose tolerance; SF-36: 36-Item Short Form Health Survey; CES-D: Center for Epidemiologic Studies Depression. Lifestyle score: physical activity subscale ranges from -1 to +5 and diet subscale ranges from -12 to +15. Overweight: BMI $\geq 25-29.9 \mathrm{Kg} / \mathrm{m}^{2}$; Obesity: BMI $\geq 30 \mathrm{Kg} / \mathrm{m}^{2}$. Questionnaires in the postpartum period were only administered by women with GDM who attended the OGTT. Categorical variables are presented as frequencies $\%(n)$; continuous variables are presented as mean \pm SD if normally distributed and as median \pm IQR if not normally distributed; Odds ratios with $95 \%$ confidence intervals are presented for significant differences; Differences are considered significant at $p$-value $<0.05$.

${ }^{a}$ For these variables, data were missing in $5-10 \%$ of all participants

${ }^{b}$ For these variables, data were missing in $10-15 \%$ of all participants

${ }^{c}$ For this variable, data was missing in $15-20 \%$ of all participants 
Table 3: Comparison of characteristics and pregnancy outcomes of women with NGT and depression versus women with NGT without depression

\begin{tabular}{|c|c|c|c|}
\hline & $\begin{array}{l}\text { NGT with depression } \\
N=239 \\
(15.1 \%)\end{array}$ & $\begin{array}{l}\text { NGT without depression } \\
N=1342 \\
(84.9 \%)\end{array}$ & p-value \\
\hline \multicolumn{4}{|l|}{ General characteristics } \\
\hline Mean age (years) & $30.4 \pm 4.5$ & $30.6 \pm 3.8$ & 0.332 \\
\hline$\%$ Non-Caucasian & $18.8(45)$ & $6.1(81)$ & $<0.001$ \\
\hline$\%$ Multiparity & $49.4(118)$ & $46.1(619)$ & 0.354 \\
\hline $\begin{array}{l}\text { \% Highest Education: } \\
\text { Primary school } \\
\text { Till } 15 \text { years } \\
\text { High school } \\
\text { Bachelor } \\
\text { Master }\end{array}$ & $\begin{array}{l}1.3(3) \\
9.9(23) \\
26.7(62) \\
35.8(83) \\
26.3(61)\end{array}$ & $\begin{array}{l}0.9(12) \\
3.2(43) \\
14.9(198) \\
43.4(576) \\
37.5(498)\end{array}$ & $<0.001$ \\
\hline$\%$ Paid job & 79.8 (189) & $94.0(1258)$ & $<0.001$ \\
\hline \% Smoking during pregnancy & $5.4(13)$ & $2.9(39)$ & 0.044 \\
\hline $\begin{array}{l}\% \text { First degree family history } \\
\text { of diabetes }\end{array}$ & $16.8(39)$ & $11.2(146)$ & 0.015 \\
\hline$\%$ History of depression & $2.5(6)$ & $0.7(9)$ & 0.017 \\
\hline \multicolumn{4}{|l|}{ 6-14 weeks of pregnancy } \\
\hline $\begin{array}{l}\text { BMI at first prenatal visit } \\
\left(\mathrm{Kg} / \mathrm{m}^{2}\right)\end{array}$ & $25.1 \pm 4.7$ & $24.2 \pm 4.4$ & 0.003 \\
\hline HOMA-IR & $9.8(6.7-14.4)$ & $9.0(6.4-12.7)$ & 0.041 \\
\hline $\begin{array}{l}\text { Fasting Total cholesterol } \\
(\mathrm{mmol} / \mathrm{l})\end{array}$ & $4.7(4.1-5.3)$ & $4.7(4.2-5.2)$ & 0.963 \\
\hline Fasting HDL (mmol/l) & $1.7(1.5-1.9)$ & $1.8(1.6-2.0)$ & 0.026 \\
\hline Fasting LDL (mmol/l) & $2.4(2.0-2.9)$ & $2.4(2.0-2.9)$ & 0.489 \\
\hline Fasting TG $(\mathrm{mmol} / \mathrm{l})$ & $1.0(0.9-1.3)$ & $1.0(0.8-1.2)$ & 0.020 \\
\hline \multicolumn{4}{|l|}{ 24-28 weeks of pregnancy } \\
\hline Fasting glycemia $(\mathrm{mmol} / \mathrm{l})$ & $4.3(4.2-4.6)$ & $4.3(4.1-4.5)$ & 0.031 \\
\hline 1-hour glucose OGTT (mmol/l) & $7.0(6.0-7.9)$ & $6.8(5.9-7.8)$ & 0.124 \\
\hline 2-hour glucose OGTT ( $\mathrm{mmol} / \mathrm{l})$ & $6.2(5.3-7.3)$ & $6.0(5.1-6.8)$ & 0.049 \\
\hline $\mathrm{HbA1c}(\mathrm{mmol} / \mathrm{mol}, \%)$ & $\begin{array}{l}30.1(29.0-32.2) \\
4.9(4.8-5.1)\end{array}$ & $\begin{array}{l}30.1(27.9-32.2) \\
4.9(4.7-5.1)\end{array}$ & 0.004 \\
\hline HOMA-IR & $13.0(9.3-19.6)$ & $11.7(8.5-16.3)$ & 0.015 \\
\hline $\begin{array}{l}\text { Fasting Total Cholesterol } \\
(\mathrm{mmol} / \mathrm{l})\end{array}$ & $6.2(5.6-7.0)$ & $6.3(5.7-7.1)$ & 0.152 \\
\hline Fasting HDL (mmol/l) & $1.8(1.6-2.1)$ & $1.9(1.7-2.3)$ & $<.001$ \\
\hline Fasting LDL (mmol/l) & $3.4(2.9-4.1)$ & $3.5(2.9-4.2)$ & 0.306 \\
\hline Fasting TG (mmol/l) & $1.9(1.5-2.5)$ & $1.8(1.4-2.2)$ & $<.001$ \\
\hline $\begin{array}{l}\text { Lifestyle score: } \\
\text { Physical activity } \\
\text { Diet }\end{array}$ & $\begin{array}{l}1.0(0.0-2.0) \\
2.0(-1.0-4.0)\end{array}$ & $\begin{array}{l}1.0(0.0-2.0) \\
2.0(0.0-4.0)\end{array}$ & $\begin{array}{l}0.851 \\
0.243\end{array}$ \\
\hline $\begin{array}{l}\text { METs category: } \\
\text { \% Low } \\
\% \text { Moderate } \\
\% \text { High }\end{array}$ & $\begin{array}{l}15.0(34) \\
45.8(104) \\
39.2(89)\end{array}$ & $\begin{array}{l}16.5(214) \\
47.5(615) \\
36.0(467)\end{array}$ & 0.631 \\
\hline IPAQ & & & \\
\hline
\end{tabular}




\begin{tabular}{|c|c|c|c|}
\hline Total work & $0.0(0.0-480.0)$ & $0.0(0.0-600.0)$ & 0.207 \\
\hline Total transport & $297.0(66.0-693.0)$ & $346.5(99.0-792.0)$ & 0.177 \\
\hline Total garden+household & $840.0(330.0-2160.0)$ & $720.0(270.0-1470.0)$ & 0.041 \\
\hline Total leisure & $99.0(0.0-420.0)$ & $198.0(0.0-495.0)$ & 0.042 \\
\hline Total walking & $594.0(198.0-1056.0)$ & 519.7 (198.0-1188.0) & 0.882 \\
\hline Total moderate & $1350.0(570.0-3030.0)$ & $1200.0(540.0-2580.0)$ & 0.346 \\
\hline Total Vigorous & $0.0(0.0-0.0)$ & $0.0(0.0-0.0)$ & 0.169 \\
\hline Total overall & $2211.0(1116.0-4836.0)$ & $2203.5(1137.0-4360.0)$ & 0.602 \\
\hline \multicolumn{4}{|l|}{ Delivery } \\
\hline $\begin{array}{l}\text { \% Excessive GWG (first visit - } \\
\text { delivery) }\end{array}$ & $37.1(79)$ & $29.4(345)$ & 0.083 \\
\hline $\begin{array}{l}\text { \% Excessive GWG } \\
\text { (prepregnancy - delivery) }^{c}\end{array}$ & $46.8(95)$ & 38.9 (439) & 0.090 \\
\hline Gestational age (weeks) & $39.4 \pm 1.6$ & $39.3 \pm 1.6$ & 0.640 \\
\hline$\%$ Preeclampsia & $3.4(8)$ & $1.5(20)$ & 0.046 \\
\hline \% Gestational hypertension & $3.4(8)$ & $4.4(59)$ & 0.453 \\
\hline$\%$ Preterm delivery & $4.7(11)$ & $5.4(72)$ & 0.654 \\
\hline$\%$ Induction labor & $31.7(75)$ & $24.7(330)$ & 0.023 \\
\hline$\%$ Forceps or vacuum & $12.2(29)$ & $12.3(165)$ & 0.961 \\
\hline$\%$ Cesarean sections (total) & $21.1(50)$ & $19.9(266)$ & 0.674 \\
\hline$\%$ Macrosomia (>4Kg) & $11.0(26)$ & $9.2(123)$ & 0.385 \\
\hline$\%$ LGA & $11.4(27)$ & $13.0(174)$ & 0.499 \\
\hline$\%$ SGA & $5.5(13)$ & $4.9(65)$ & 0.682 \\
\hline$\%$ Apgar 10min <7 & $0.0(0)$ & $1.1(15)$ & 0.102 \\
\hline \%Shoulder dystocia & $0.4(1)$ & $1.3(17)$ & 0.257 \\
\hline$\%$ Congenital anomaly & $3.0(7)$ & $4.3(57)$ & 0.356 \\
\hline $\begin{array}{l}\text { \% Respiratory Distress } \\
\text { syndrome }\end{array}$ & $0.8(2)$ & $1.0(13)$ & 0.849 \\
\hline $\begin{array}{l}\text { \%Neonatal hypoglycemia } \\
<2.2 \mathrm{mmol} / \mathrm{l}\end{array}$ & $3.1(5)$ & $4.1(35)$ & 0.664 \\
\hline \% Neonatal jaundice & $19.5(33)$ & $19.1(182)$ & 0.916 \\
\hline \% NICU admission & $11.2(26)$ & $9.2(123)$ & 0.352 \\
\hline Days on NICU & $9.6 \pm 18.8$ & $8.3 \pm 13.0$ & 0.636 \\
\hline \multicolumn{4}{|l|}{ Postpartum } \\
\hline \multicolumn{4}{|l|}{ SF-36 } \\
\hline Physical functioning & $85.0(75.0-95.0)$ & $90.0(85.0-100.0)$ & $<0.001$ \\
\hline Role physical & $62.5(43.7-93.7)$ & 87.5 (68.7- 100.0) & $<0.001$ \\
\hline Role Emotional & $66.7(41.7-83.3)$ & $100.0(75.0-100.0)$ & $<0.001$ \\
\hline Energy & $43.7(37.5-56.2)$ & $62.5(50.0-75.0)$ & $<0.001$ \\
\hline Emotional well-being & $65.0(55.0-70.0)$ & $70.0(65.0-75.0)$ & $<0.001$ \\
\hline Social functioning & $62.5(50.0-87.5)$ & $87.5(75.0-100.0)$ & $<0.001$ \\
\hline Pain & $77.5(66.2-90.0)$ & $90.0(77.5-100.0)$ & $<0.001$ \\
\hline General Health & $65.0(50.0-75.0)$ & $75.0(65.0-85.0)$ & $<0.001$ \\
\hline Health Transition & $50.0(25.0-50.0)$ & $50.0(50.0-50.0)$ & 0.054 \\
\hline
\end{tabular}

NGT: normal glucose tolerance; OR: odds ratio; Cl: confidence interval; BMI: Body Mass Index; OGTT: oral glucose tolerance test; HDL: high-density lipoprotein; LDL: low-density-lipoprotein; TG: triglycerides; MET: metabolic equivalent of task; GWG: gestational weight gain; LGA: large-for-gestational age infant; SGA: smallfor-gestational age infant; NICU: neonatal intensive care unit; IFG: impaired fasting glycemia; IGT: impaired 
glucose tolerance; SF-36: 36-Item Short Form Health Survey; CES-D: Center for Epidemiologic Studies Depression. Lifestyle score: physical activity subscale ranges from -1 to +5 and diet subscale ranges from -12 to +15. Overweight: $\mathrm{BMI} \geq 25-29.9 \mathrm{Kg} / \mathrm{m}^{2}$; Obesity: $\mathrm{BMI} \geq 30 \mathrm{Kg} / \mathrm{m}^{2}$. Categorical variables are presented as frequencies $\%(n)$; continuous variables are presented as mean \pm SD if normally distributed and as median \pm IQR if not normally distributed; Odds ratios with 95\% confidence intervals are presented for significant differences; Differences are considered significant at $p$-value $<0.05$.

${ }^{b}$ For these variables, data were missing in $10-15 \%$ of all participants

${ }^{c}$ For this variable, data was missing in $15-20 \%$ of all participants 
Table 4: Characteristics of depressed versus non-depressed women in the total cohort

\begin{tabular}{|c|c|c|c|}
\hline & $\begin{array}{l}\text { Depressed women } \\
N=293 \\
(16.1 \%)\end{array}$ & $\begin{array}{l}\text { Non-depressed women } \\
N=1530 \\
(83.9 \%)\end{array}$ & $p$-value \\
\hline \multicolumn{4}{|l|}{ General characteristics } \\
\hline Mean age (years) & $30.7 \pm 4.7$ & $30.8 \pm 3.9$ & 0.373 \\
\hline$\%$ Non-Caucasian & $21.2(62)$ & $7.4(112)$ & $<0.001$ \\
\hline \% Multiparity & $50.5(148)$ & 47.0 (719) & 0.269 \\
\hline $\begin{array}{l}\text { \% Highest Education }{ }^{a} \text { : } \\
\text { Primary school } \\
\text { Till } 15 \text { years } \\
\text { High school } \\
\text { Bachelor } \\
\text { Master }\end{array}$ & $\begin{array}{l}2.1(6) \\
9.6(27) \\
26.0(73) \\
35.9(101) \\
26.3(74)\end{array}$ & $\begin{array}{l}1.0(15) \\
3.4(51) \\
15.7(237) \\
42.5(641) \\
37.4(563)\end{array}$ & $<0.001$ \\
\hline Paid job & $80.3(233)$ & $93.6(1425)$ & $<0.001$ \\
\hline \% Smoking during pregnancy & $6.8(20)$ & $3.0(46)$ & 0.001 \\
\hline History of depression & $2.7(8)$ & $0.9(13)$ & 0.012 \\
\hline $\begin{array}{l}\text { BMI at first prenatal visit } \\
\left(\mathrm{Kg} / \mathrm{m}^{2}\right)\end{array}$ & $25.7 \pm 5.0$ & $24.5 \pm 4.6$ & $<0.001$ \\
\hline \multicolumn{4}{|l|}{ 24-28 weeks of pregnancy } \\
\hline Fasting glycaemia (mmol/l) & $4.4(4.2-4.7)$ & $4.3(4.1-4.6)$ & 0.002 \\
\hline $\begin{array}{l}\text { 1-hour glucose OGTT } \\
\text { (mmol/l) }\end{array}$ & $7.3(6.1-8.5)$ & $7.1(6.1-8.2)$ & 0.042 \\
\hline $\begin{array}{l}\text { 2-hour glucose OGTT } \\
(\mathrm{mmol} / \mathrm{l})\end{array}$ & $6.4(5.4-7.6)$ & $6.2(5.2-7.1)$ & 0.006 \\
\hline $\mathrm{HbA1c}(\mathrm{mmol} / \mathrm{mol}, \%)$ & $\begin{array}{l}31.1(29.0-33.3) \\
5.0(4.8-5.2)\end{array}$ & $\begin{array}{l}30.1(29.0-32.2) \\
4.9(4.8-5.1)\end{array}$ & $<0.001$ \\
\hline $\begin{array}{l}\text { Fasting Total Cholesterol } \\
(\mathrm{mmol} / \mathrm{l})\end{array}$ & $6.1(5.5-7.0)$ & $6.3(5.7-7.1)$ & 0.063 \\
\hline Fasting HDL (mmol/l) & $1.8(1.6-2.1)$ & $1.9(1.7-2.3)$ & $<0.001$ \\
\hline Fasting LDL (mmol/l) & $3.3(2.8-4.0)$ & $3.5(2.9-4.1)$ & 0.087 \\
\hline Fasting TG (mmol/l) & $2.0(1.5-2.5)$ & $1.8(1.5-2.3)$ & $<0.001$ \\
\hline $\begin{array}{l}\text { Lifestyle score: } \\
\text { Physical activity } \\
\text { Diet }\end{array}$ & $1.0(0.0-2.0)$ & $\begin{array}{l}1.0(0.0-2.0) \\
2.0(0.0-4.0)\end{array}$ & $\begin{array}{l}0.970 \\
\mathbf{0 . 0 3 2}\end{array}$ \\
\hline $\begin{array}{l}\text { METs category }{ }^{\mathrm{a}} \text { : } \\
\text { Low } \\
\text { Moderate } \\
\text { High }\end{array}$ & $\begin{array}{l}16.5(46) \\
45.9(128) \\
37.6(105)\end{array}$ & $\begin{array}{l}16.6(245) \\
46.9(691) \\
36.5(539)\end{array}$ & 0.939 \\
\hline \multicolumn{4}{|l|}{ Delivery } \\
\hline $\begin{array}{l}\text { \% Excessive GWG (first visit - } \\
\text { delivery) }\end{array}$ & $34.1(87)$ & $28.1(375)$ & 0.147 \\
\hline $\begin{array}{l}\text { \% Excessive GWG } \\
\text { (prepregnancy - delivery) }^{c}\end{array}$ & $44.5(109)$ & $37.3(478)$ & 0.093 \\
\hline Gestational age (weeks) & $39.3 \pm 1.6$ & $39.2 \pm 1.6$ & 0.901 \\
\hline \% Preeclampsia & $2.8(8)$ & $1.5(23)$ & 0.132 \\
\hline \% Gestational hypertension & $3.8(11)$ & $4.3(65)$ & 0.716 \\
\hline$\%$ Preterm delivery & $5.2(15)$ & $5.6(85)$ & 0.821 \\
\hline$\%$ Induction labor & $30.6(88)$ & $26.4(403)$ & 0.146 \\
\hline \% Forceps or vacuum & $12.2(35)$ & $12.2(186)$ & 0.980 \\
\hline \% Cesarean sections (total) & $22.9(66)$ & $20.4(311)$ & 0.336 \\
\hline
\end{tabular}




\begin{tabular}{|c|c|c|c|}
\hline \% Macrosomia (>4Kg) & $10.1(29)$ & $9.1(138)$ & 0.565 \\
\hline$\%$ LGA & $11.9(34)$ & $12.9(197)$ & 0.612 \\
\hline$\%$ SGA & $4.9(14)$ & $4.9(75)$ & 0.968 \\
\hline$\%$ Apgar $10 \min <7$ & $0.0(0)$ & $1.1(16)$ & 0.081 \\
\hline \%Shoulder dystocia & $0.7(2)$ & $1.2(18)$ & 0.469 \\
\hline$\%$ Congenital anomaly & $3.2(9)$ & $4.4(66)$ & 0.359 \\
\hline $\begin{array}{l}\% \text { Respiratory Distress } \\
\text { syndrome }\end{array}$ & $0.7(2)$ & $1.0(15)$ & 0.638 \\
\hline $\begin{array}{l}\text { \%Neonatal hypoglycemia } \\
<2.2 \mathrm{mmol} / \mathrm{l}\end{array}$ & $4.0(8)$ & $5.9(60)$ & 0.318 \\
\hline \% Neonatal jaundice & $18.0(36)$ & $18.8(204)$ & 0.844 \\
\hline$\%$ NICU admission & $10.9(31)$ & $9.9(150)$ & 0.585 \\
\hline Days on NICU & $8.9 \pm 17.3$ & $8.1 \pm 12.4$ & 0.819 \\
\hline \multicolumn{4}{|l|}{ Postpartum } \\
\hline \multicolumn{4}{|l|}{ SF-36 } \\
\hline Physical functioning & $85.0(70.0-95.0)$ & $90.0(85.0-100.0)$ & $<0.001$ \\
\hline Role physical & $68.8(43.8-93.8)$ & $87.5(68.8-100.0)$ & $<0.001$ \\
\hline Role Emotional & $66.7(50.0-100.0)$ & $100.0(75.0-100.0)$ & $<0.001$ \\
\hline Energy & $50.0(37.5-56.2)$ & $62.5(50.0-75.0)$ & $<0.001$ \\
\hline Emotional well-being & $65.0(55.0-70.0)$ & $70.0(65.0-75.0)$ & $<0.001$ \\
\hline Social functioning & $75.0(50.0-87.5)$ & $87.5(75.0-100.0)$ & $<0.001$ \\
\hline Pain & 77.5 (67.5- 100.0) & $90.0(77.5-100.0)$ & $<0.001$ \\
\hline General Health & $65.0(50.0-75.0)$ & $75.0(65.0-85.0)$ & $<0.001$ \\
\hline Health Transition & $50.0(25.0-50.0)$ & $50.0(50.0-50.0)$ & 0.057 \\
\hline
\end{tabular}

OR: odds ratio; $\mathrm{Cl}$ : confidence interval;; BMI: Body Mass Index; OGTT: oral glucose tolerance test; HDL: highdensity lipoprotein; LDL: low-density-lipoprotein; TG: triglycerides; MET: metabolic equivalent of task; GWG: gestational weight gain; LGA: large-for-gestational age infant; SGA: small-for-gestational age infant; NICU: neonatal intensive care unit; IFG: impaired fasting glycemia; IGT: impaired glucose tolerance; SF-36: 36-Item Short Form Health Survey; CES-D: Center for Epidemiologic Studies - Depression. Lifestyle score: physical activity subscale ranges from -1 to +5 and diet subscale ranges from -12 to +15 . Overweight: BMI $\geq 25-29.9$ $\mathrm{Kg} / \mathrm{m}^{2}$; Obesity: $\mathrm{BMI} \geq 30 \mathrm{Kg} / \mathrm{m}^{2}$. Categorical variables are presented as frequencies $\%(\mathrm{n})$; continuous variables are presented as mean \pm SD if normally distributed and as median \pm IQR if not normally distributed; Differences are considered significant at $p$-value $<0.05$.

${ }^{a}$ For these variables, data were missing in $5-10 \%$ of all participants

${ }^{b}$ For these variables, data were missing in $10-15 \%$ of all participants

${ }^{\mathrm{c}}$ For this variable, data was missing in $15-20 \%$ of all participants 
Table 5: The association between antenatal depression and pregnancy outcomes in the total cohort

\begin{tabular}{|l|l|l|}
\hline & OR or MD (95\% Cl) & p-value \\
\hline Excessive GWG (first visit - delivery) & $1.33(1.00 ; 1.77)$ & $\mathbf{0 . 0 5 1}$ \\
\hline Excessive GWG (prepregnancy - delivery) & $1.36(1.03 ; 1.79)$ & $\mathbf{0 . 0 3 3}$ \\
\hline Gestational age (weeks) & $0.03(-0.17 ; 0.24)$ & 0.747 \\
\hline Preeclampsia & $1.87(0.83 ; 4.23)$ & 0.131 \\
\hline Gestational Hypertension & $0.90(0.47 ; 1.72)$ & 0.740 \\
\hline Preterm Delivery & $0.95(0.54 ; 1.67)$ & 0.851 \\
\hline Induction Labor & $1.27(0.96 ; 1.67)$ & 0.094 \\
\hline Forceps or vacuum & $1.01(0.69 ; 1.48)$ & 0.972 \\
\hline Caesarean section (total) & $1.18(0.87 ; 1.60)$ & 0.283 \\
\hline Planned CS & $1.01(0.67 ; 1.53)$ & 0.963 \\
\hline Emergency CS (during labor) & $1.32(0.89 ; 1.94)$ & 0.167 \\
\hline Postpartum blood loss & & \\
\hline > 50Oml & $1.05(0.78 ; 1.42)$ & 0.753 \\
\hline > 1000ml & $1.32(0.63 ; 2.77)$ & 0.461 \\
\hline Macrosomia (>4Kg) & $1.19(0.79 ; 1.80)$ & 0.402 \\
\hline LGA & $0.93(0.63 ; 1.37)$ & 0.698 \\
\hline SGA & $1.00(0.56 ; 1.79)$ & 0.997 \\
\hline Shoulder Dystocia & $0.59(0.14 ; 2.56)$ & 0.483 \\
\hline Congenital anomaly & $0.73(0.36 ; 1.48)$ & 0.378 \\
\hline Respiratory Distress Syndrome & $0.71(0.16 ; 3.12)$ & 0.650 \\
\hline Neonatal hypoglycemia $<2.2$ mmol/I & $0.67(0.32 ; 1.42)$ & 0.296 \\
\hline Neonatal Jaundice & $0.98(0.66 ; 1.45)$ & 0.903 \\
\hline NICU admission & $1.13(0.75 ; 1.71)$ & 0.547 \\
\hline Days on NICU & $0.83(-4.52 ; 6.19)$ & 0.759 \\
\hline
\end{tabular}

OR: odds ratio; MD: mean difference; GWG: gestational weight gain; CS: cesarean sections; LGA: large-forgestational age infant; SGA: small-for-gestational age infant; NICU: neonatal intensive care unit; Odds ratios with $95 \%$ confidence intervals are presented for binary outcomes whereas mean differences with $95 \%$ confidence intervals are presented for continuous pregnancy outcomes; An odds ratio $>(<) 1$ means a higher (lower) risk of the event for depressed participants. A mean difference $>(<) 0$ means a higher (lower) outcome level for depressed participants. Differences are considered significant at $p$-value $<0.05$. 
A. With gestational weight gain based on self-reported prepregnancy weight

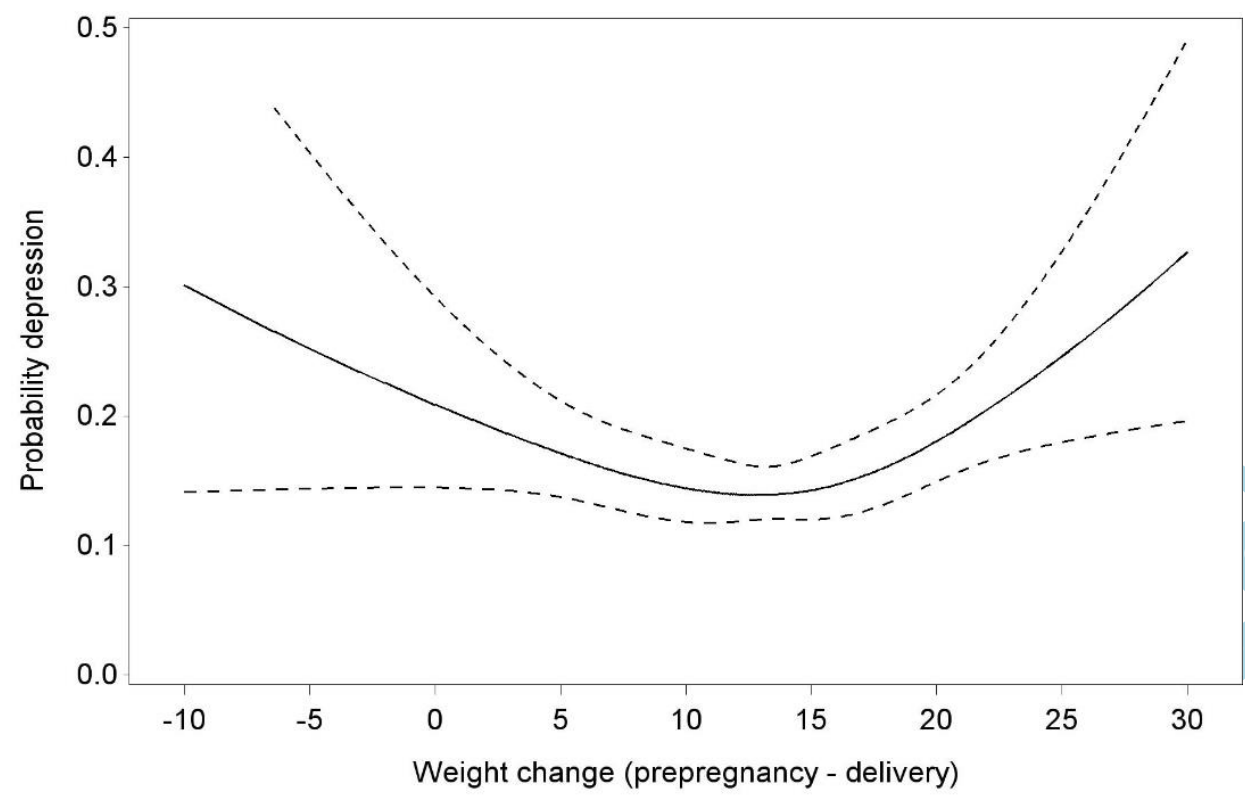

Dotted lines: 95\% confidence interval. Weight change (in kgs) was determined with respect to the self-reported prepregnancy weight.

B. With gestational weight gain based on weight at first visit (6-14 weeks of pregnancy)

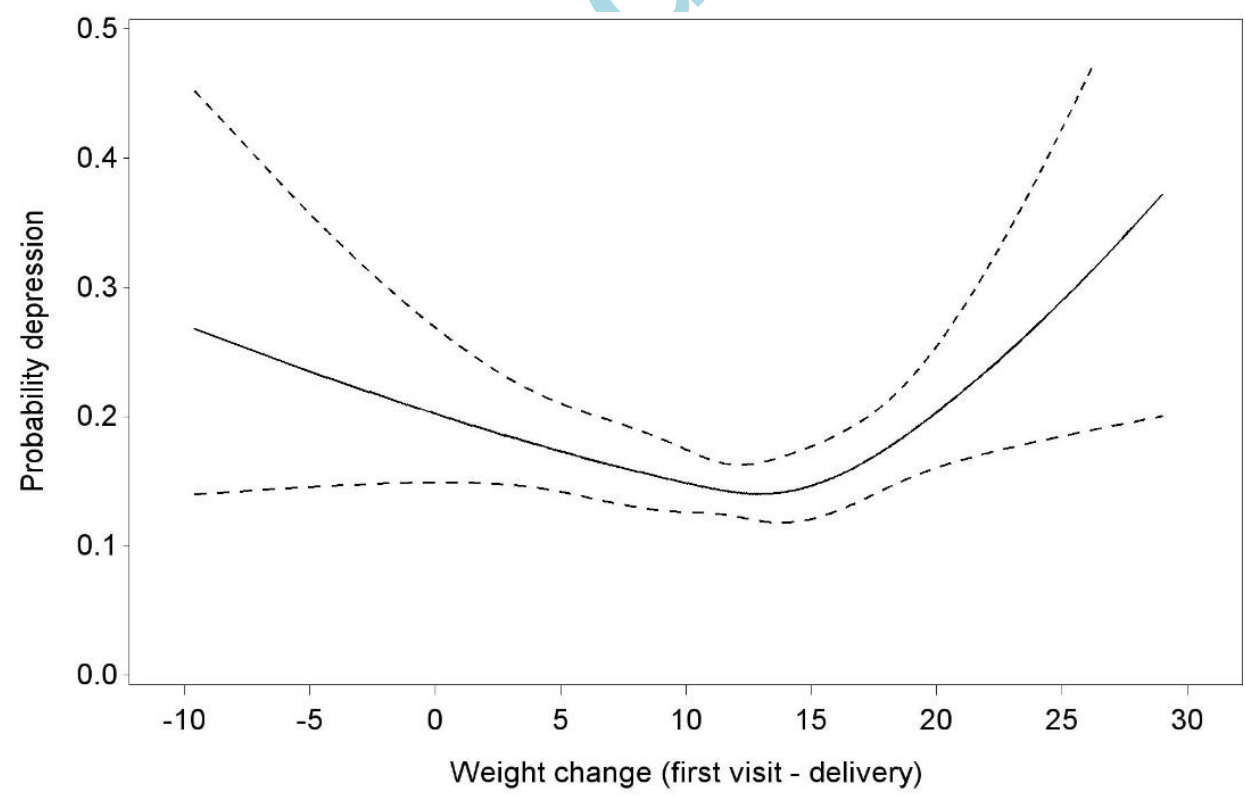

Dotted lines: $95 \%$ confidence interval. Weight change (in $\mathrm{kgs}$ ) was determined with respect to the weight measured at first visit in early pregnancy. 